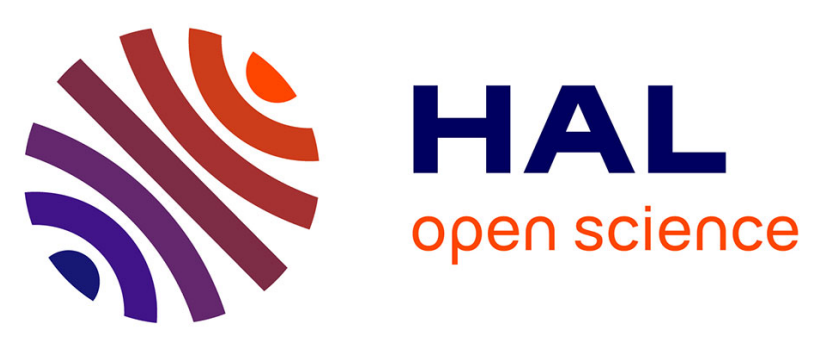

\title{
THE Cu I AND Zn I-LIKE SPECTRA OF Pr, Eu, Gd, Dy AND Yb EMITTED BY A TOKAMAK PLASMA IN THE 50-200 ̊̊ RANGE
}

W. Hodge, M. Finkenthal, H. Moos, S. Lippmann, L. Huang, A. Bar-Shalom, M. Klapisch

\section{To cite this version:}

W. Hodge, M. Finkenthal, H. Moos, S. Lippmann, L. Huang, et al.. THE Cu I AND Zn I-LIKE SPECTRA OF Pr, Eu, Gd, Dy AND Yb EMITTED BY A TOKAMAK PLASMA IN THE 50-200 RANGE. Journal de Physique Colloques, 1988, 49 (C1), pp.C1-75-C1-77. 10.1051/jphyscol:1988114 . jpa-00227434

\section{HAL Id: jpa-00227434 https://hal.science/jpa-00227434}

Submitted on 1 Jan 1988

HAL is a multi-disciplinary open access archive for the deposit and dissemination of scientific research documents, whether they are published or not. The documents may come from teaching and research institutions in France or abroad, or from public or private research centers.
L'archive ouverte pluridisciplinaire HAL, est destinée au dépôt et à la diffusion de documents scientifiques de niveau recherche, publiés ou non, émanant des établissements d'enseignement et de recherche français ou étrangers, des laboratoires publics ou privés. 
JOURNAL DE PHYSIQUE

Colloque $\mathrm{Cl}$, Supplément au $\mathrm{n}^{\circ} 3$, Tome 49, Mars 1988

THE Cu I AND Zn I-LIKE SPECTRA OF Pr, Eu, Gd, DY AND Yb EMITTED BY A TOKAMAK PLASMA IN THE 50-200 \& RANGE

\author{
W.I. HODGE(1), M. FINKENTHAL (2), H.W. MOOS, S. LIPPMANN, \\ L.K. HUANG, A. BAR-SHALOM*, (3) and M. KLAPISCH \\ Department of Physics and Astronomy. The Johns Hopkins \\ University, Baltimore, MD 21218, U.S.A. \\ ${ }^{*}$ Racah Institute of Physics, The Hebrew University, \\ IL-91904 Jerusalem, Israel
}

\begin{abstract}
Spectra of rare earth elements, praseodymium, europium, gadolinium, dysprosium and ytterbium $(Z=59$ to $Z=70)$ have been recorded from a high temperature $(T=1-1.4$ $\mathrm{keV})$ - low density $\left(\mathrm{n}=10^{13} \mathrm{~cm}^{-3}\right)$ tokamak plasma, in the 50-200 A range. The absolute brightnesses of the lines originating in 4-4 transitions of $\mathrm{Cu} I$ and $\mathrm{Zn} I-I$ ike ions of the above mentioned elements have been measured by means of a photometrically calibrated grazing incidence spectrometer. Newly identified Cu I-like,

$4 s^{2} S_{1-2}-4 p_{-2}^{2} P_{1-2}$ transitions in $\mathrm{Pr}^{30^{+}}, \mathrm{Eu}^{34}, \mathrm{Gd}^{35^{+}}, \mathrm{Dy}^{37^{+}}$and $\mathrm{Yb}^{41}$, and intercombination transitions $4 \mathrm{~s}^{2}{ }^{1} \mathrm{~S}_{0}-4 \mathrm{~s} 4 \mathrm{p}{ }^{3} \mathrm{P}_{1}$ in the $\mathrm{Zn}$ I-1ike ions of the mentioned elements are presented. The identifications are based on interpolation of previous experimental results, ab initio energy level computations using the RELAC code and are substantiated by the time histories of individual spectral lines. The experimental line intensities of the $C U \mathrm{I}$ and $\mathrm{Zn}$ I-like ions are compared with those predicted by a collisional-radiative model under the conditions of the tokamak plasma.
\end{abstract}

The present work was motivated by the potential use of $\mathrm{Cu} I$ and $\mathrm{Zn} I$-Iike lines of the rare earth ions as electron density diagnostics of high temperature plasmas. Many of the lines of interest have been previously identified by Reader and Luther (1981) and Doschek et al. (1987) for the copper isoelectronic sequence. In the $\mathrm{Zn} I-$ like sequence, the $4 \bar{s}^{2}{ }^{1} S_{0}-4 s 4 p^{1} P_{1}$ ines have been identified for the elements of interest by Reader and Luther (1980) and Acquista and Reader (1984). Recently, Hinnov et al. (1987), have measured intercombination lines of rare earth ions, isoelectronic with $\mathrm{Zn} \mathrm{I.} \mathrm{However,} \mathrm{one} \mathrm{of} \mathrm{the} \mathrm{elements} \mathrm{we} \mathrm{were} \mathrm{interested} \mathrm{in,}$ europium, has not been investigated by Reader and Luther (1981). We measured and identified in the spectra emitted by the TEXT tokamak plasma, lines emitted by $4 \mathrm{~s}-4 \mathrm{p}$, $4 p-4 d$ and $4 d-4 f$ transitions of $E_{\mu^{34}}{ }^{7}$. Also, the $4 s^{2} S_{1 / 2}-4 p^{2} P_{1 / 2}$ transitions in $\mathrm{Pr}^{30^{+}}, \mathrm{Eu}^{34^{+}}, \mathrm{Gd}^{35^{+}}, \mathrm{Dy}^{37^{+}}$and $\mathrm{Yq}^{41^{+}}$are identified for the first time in the present work. Zn I-Iike, $\mathrm{Gd}^{34^{+}}, \mathrm{Dy}^{36^{+}}$and $\mathrm{Yb}^{40^{+}}$intercombination lines emitted within $4 \mathrm{~s}^{2}$ ${ }^{1} \mathrm{~S}_{0}-4 \mathrm{~s} 4 \mathrm{p}{ }^{3} \mathrm{P}_{1}$ transitions have been identified.

$\mathrm{Ab}$ initio energy level computations using the relativistic parametric potential code RELAC (Klapisch et al. 1979) have been used to predict the wavelengths of the $\mathrm{Cu}$ I-like and the $\mathrm{Zn} I-I i \overline{k e}$ lines. Also predicted wavelengths of the forbidden (M1) lines ${ }^{3} \mathrm{P}_{2} \rightarrow{ }^{3} \mathrm{P}_{1}$ within the $4 \mathrm{~s} 4 \mathrm{p}{ }^{3} \mathrm{P}$ multiplet and magnetic quadrupole (M2) 1 ines originating from the $4 \mathrm{~s}^{2}{ }^{1} \mathrm{~S}_{0}-4 \mathrm{~s} 4 \mathrm{p}{ }^{3} \mathrm{P}_{2}$ transition are included in the present work.

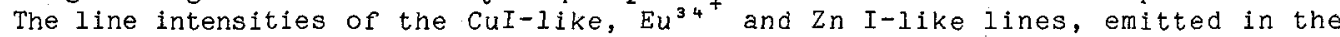
tokamak spectra have been compared with predictions of a collisional radiative model. (The model is discussed in a recent paper of the authors (Finkenthal et al. 1987).

The rare earth elements have been introduced in the TEXT tokamak (at Fusion Research Center, Austin) by the laser blow-off technique (D.R. Terry et al. 1983). The experimental conditions are similar to those described by Finkenthal et al. (1986).

The spectra, in the 50-200 $\AA$ range, were recorded by a grazing incidence timeresolving spectrograph, GRITS (Hodge, Stratton and Moos 1984).

\footnotetext{
(1) Present address : High Energy Laser Associates, Piedmont, CA 94611, U.S.A.

${ }^{(2)}$ Permanent address : Racah Institute of Physics. The Hebrew University. IL-91904 Jerusalem, Israel

(3) Permanent address : Nuclear Research Center of Negev, Beer-Sheva, Israel
} 
Figure 1 shows the spectra of europium, gadolinium and dysprosium between 54 and $106 \AA$. All the spectra show a similar pattern: a band at the shorter wavelength side and a relatively narrow region containing a few bright lines. These bands have been analyzed in a previous wprk (Finkenthal et al. 1986) and shown to originate in $4 d^{k}$ $4 \mathrm{~d}^{\mathrm{k}} 4 \mathrm{f}$ and $4 \mathrm{p}^{6} 4 \mathrm{~d}^{\mathrm{k}}-4 \mathrm{p}^{5} 4 \mathrm{~d}^{\mathrm{k}+}$ transitions of ions isoelectronic with $\mathrm{PQ} I$ to $\mathrm{Rb}$ I. The line spectrum, at the longer wavelength side is dominated by the resonance transitions in the $\mathrm{Cu} I$ and $\mathrm{Zn}$ I-like ions.

Table 1 presents the identification of the $\mathrm{Eu}^{34^{+}}$lines. Besides the ab initio calculations, interpolated values from the work of Reader and Luther (1981) were used to predict the wavelengths. The identification was quite straightforward for the strong lines presented in the table.

Table 2 presents the newly identified $4 \mathrm{~S}^{2} \mathrm{~S}_{1} 2_{2}-4 \mathrm{P}{ }^{2} \mathrm{P}_{1 / 2}$ transitions in $\mathrm{Pr}^{3} 0^{+}$, $\mathrm{Eu}^{34^{+}}, \mathrm{Gd}^{35}, \mathrm{Dy}^{37}$ and $\mathrm{Yb}^{41}$ ions. If the populations of the two levels ${ }^{2} \mathrm{P}_{1 / 2}$ and ${ }^{2} \mathrm{P}_{3 / 2}$ would be at Boltzmann equilibrium, the lines under discussion would be an order of magnitude weaker that those originating from the $4 \mathrm{~s}^{2} \mathrm{~S}_{1 / 2}-4 \mathrm{p}^{2} \mathrm{P}_{3 / 2}$ transitions. However, at the relatively low tokamak densities the relative brightness ratios are quite different as indicated in the table for three different ions, $\mathrm{Pr}^{3} 0^{+}$, $\mathrm{Eu}^{34^{+}}$and $\mathrm{Yb}^{41^{+}}$. The lines being weli separated, we assume an accuracy of 0.15 \& in the wavelength measurements. In order to confirm the identification, time histories of the lines under discussion have been compared with those already known emitted by the same ions.

The Zn I-like "intercombination" lines emitted within the $4 \mathrm{~s}^{2}{ }^{1} \mathrm{~S}_{0}-4 \mathrm{~s} 4 \mathrm{p}{ }^{3} \mathrm{P}_{1}$ transition become stronger as $Z$ increases since the ${ }^{3} P_{1}$ level becomes strongly mixed with the ${ }^{1} \mathrm{P}_{1}$ (therefore the transition rates to the ground ${ }^{1} \mathrm{~S}$ o become higher). Table 3 presents the computed wavelengths of the intercombination, magnetic dipole and magnetic quadrapole lines. In the present work we only present the identification of the intercombination lines; a work in progress is discussing the line intensities of singlet, intercombination and forbidden lines. The $4 \mathrm{~s}^{2}{ }^{1} \mathrm{P}-4 \mathrm{~s} 4 \mathrm{p}{ }^{3} \mathrm{P}_{1}$ lines have been identified, as in the $\mathrm{Cu}$ I-like case, by comparison with $a b$ initio interpolated values and comparison of the time histories of the candidate lines with those of the known $4 \mathrm{~s}^{2}$ ${ }^{1} \mathrm{~S}_{0}-4 \mathrm{~s} 4 \mathrm{p}{ }^{1} \mathrm{P}_{1}$ transitions.

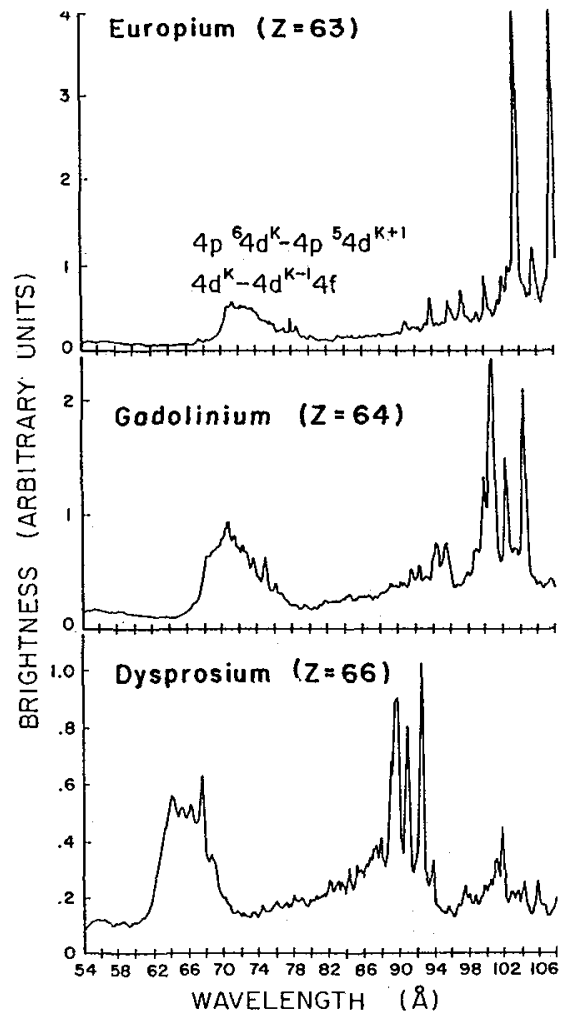

Fig. 1. The Eu, Gd and Dy spectra emitted by the TEXT tokamak in the 50-100 \& range.

Table 1: Experimental and ab initio computed wavelengths of $4-4$ transitions in $\mathrm{Eu}^{34^{+}}$.

\begin{tabular}{|c|c|c|c|c|}
\hline \multirow[t]{2}{*}{ Transition } & \multicolumn{2}{|c|}{$\lambda(\AA)$} & $\frac{\mathrm{B}\left(\mathrm{ph} / \mathrm{cm}^{2} \mathrm{sec} \mathrm{sr}\right)}{\left(\times 10^{14}\right)}$ & B (predicted) \\
\hline & predicted & measured & & $\mathrm{n}_{\mathrm{e}}=10^{13} \mathrm{~cm}^{-3} ; \mathrm{T}_{\mathrm{e}}=1000 \mathrm{eV}$ \\
\hline $4 s^{2} S_{1} 2^{-4 p^{2}} P_{3-2}$ & 107.57 & 107.7 & 7.4 & 100 \\
\hline $4 s^{2} S_{1}-4 p^{2} P_{1}$ & 171.03 & 171.6 & 4 & 59 \\
\hline $4 p^{2} P_{1}-4 d^{2} D_{3,2}$ & 78.66 & 77.9 & & 5 \\
\hline $4 p^{2} P_{3}{ }_{2}-4 d{ }^{2} D_{5}$ & 100.2 & 100.0 & 1 & 8 \\
\hline $4 P^{2} P_{3} P^{2}-4 d^{2} D_{3}$ & 107.95 & $?$ & & 0.4 \\
\hline $4 d^{2} D_{3} 2^{-4 f^{2} F_{5}}$ & 94.10 & $?$ & & 0.8 \\
\hline $4 d^{2} D_{5} z^{-4 f^{2}} F_{7}$ & 99.47 & bl & & 1.15 \\
\hline
\end{tabular}


Table 2: The 4s ${ }^{2} \mathrm{~S}_{1 / 2}-4 \mathrm{p}^{2} \mathrm{P}_{12}$ transitions in $\mathrm{Pr}^{30^{+}}, \mathrm{Eu}^{34^{+}}, \mathrm{Gd}^{35^{+}}, \mathrm{Dy}^{37^{+}} \mathrm{and}_{\mathrm{Yb}^{42}}^{+}$ ions.

\begin{tabular}{|c|c|c|}
\hline \multirow[t]{2}{*}{ Ion } & $\lambda^{*}$ pred & $\lambda_{\text {meas }}$ \\
\hline & A & $\AA$ \\
\hline $\begin{array}{l}\mathrm{Pr}^{30^{+}} \\
\mathrm{Eu}^{34^{+}} \\
\mathrm{Gd}^{35}+ \\
\mathrm{Dy}^{37^{+}} \\
\mathrm{Yb}^{41^{+}}\end{array}$ & $\begin{array}{l}194.55 \text { (RELAC) } \\
171.6 \\
166.5 \\
156.48 \text { (RELAC) } \\
140.5 \text { (139.96, RELAC) }\end{array}$ & $\begin{array}{l}195.7 \\
171.6 \\
166.8 \\
157.0 \\
140.95\end{array}$ \\
\hline
\end{tabular}

*predicted by Reader and Luther, 1981, or computed ab initio by RELAC.

Table 3: Experimental and predicted wavelengths (RELAC) of allowed and forbidden $\mathrm{Zn} \mathrm{I-like} \mathrm{lines} \mathrm{of} \mathrm{Pr}^{29^{7}}, \mathrm{Eu}^{33^{+}}, \mathrm{Gd}^{34}, \mathrm{Dy}^{36^{+}}$and $\mathrm{Yb}^{40}$

Ion

Transition

$$
\begin{gathered}
4 s^{2}{ }^{1} s_{0}-4 s 4 p^{3} P_{1} \\
\text { predicted }
\end{gathered}
$$

$\begin{array}{ll}\mathrm{Pr}^{29^{+}} & 208.5 \\ \mathrm{Eu}^{33^{+}} & 181.9 \\ \mathrm{Gd}^{34^{+}} & 176.1 \\ \mathrm{Dy}^{36} & 165.44 \\ \mathrm{Yb}^{40^{+}} & 147.2\end{array}$

$$
\begin{gathered}
4 s^{2}{ }^{1} S_{0}-4 s 4 p^{3} P_{2} \\
\text { predicted }
\end{gathered}
$$$$
\begin{aligned}
& 146.35 \\
& 117.7 \\
& 111.6 \\
& 100.4 \\
& 81.5
\end{aligned}
$$

$$
\begin{gathered}
{ }_{454}^{4}{ }^{3} \mathrm{P}_{2} \rightarrow{ }^{3} \mathrm{P}_{1} \\
\text { predicted }
\end{gathered}
$$

491.1

333.7

304.6

255.2

182.7

All the predictions are ab initio RELAC computations.

References

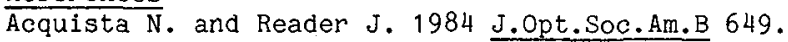

Doschek G.A., Feldman U., Brown C.M., SeeIy G.F., Ekberg J.0., Behring W.E. and Richardson M.C., submitted to J.Opt.Soc.Am.B, 1987 .

Finkenthal M., Lippmann A.S., Huang L.K., Yu T.L., Stratton B.C., Moos, H.W., Klapish M., Mandelbaum P., BarShalom A., Hodge W.L., Phillips P.E., Price T.R., Porter, J.C., Richards B. and Rowan W.L. 1986 J.Appl.Phys. 593644.

Finkenthal M., Moos H.W., BarShalom A., Spector N., Ziegler A., Yarkoni E. 1987, to be submitted J.Phys:B,At.Mol.Phys.

Hinnov E., Beiersdorfer P., Bell R., Steven J., Suckewer S., von Goeler S., Wonters A., Dietrich D., Gerassimenko M. and Silver E., 1987, Phys.Rev. A 35 4876:

Hodge W.L., Stratton B.C. and Moos H.W. 1984 Rev.Sci.Instr. 55116.

Klapish M., Schwob J.L., Fraenkel B.S., Oreg J. 1979 J.Opt.Soc.Am. 67148.

Reader J. and Luther G. 1980 Phys. Rev. Lett. 45609.

Reader J: and Luther G: 1981 Physica Scripta 24732. 